\title{
Interest and limits of assessing acute kidney injury in administrative dataset
}

\author{
Michaël Darmon ${ }^{1,2,3^{*}}$ (D) Emmanuel Canet $^{4}$ and Lara Zafrani ${ }^{1,2,5}$
}

We read with great interest the manuscript published by Hwang et al. [1]. This later reports a large national cohort of patients from 2008 to 2015 and suggests an independent increase in rate of acute kidney injury (AKI) through the study period and a trend toward a lower mortality [1]. These data are important, and a limited number of manuscripts assessed both change in incidence and prognosis of AKI over time [2]. However, significant limitations deserve to be noted and taken into account. First, these data arise from a national administrative dataset, which has displayed limited reliability. Hence, in line with findings in most of administrative dataset, major diagnosis coding reliability was found to be around $70 \%$, limiting confidence that may be put in both variables of interest and confounding variables adjusted for [3]. Along this line, AKI coding has proven being particularly insensitive, with sensitivity ranging from less than 10 to $60 \%$ [4]. Interestingly, AKI code reliability was found to be strongly associated with AKI severity, hospital unit and even gender. For example, codes for renal replacement therapy (RRT)-requiring AKI have higher sensitivity than codes for non-RRT-requiring AKI [4]. As most AKI patients do not require RRT, coding is highly dependent on AKI recognition, coding practices and case-mix [4]. In this line, change in coding reliability over time and change in coding practices induced by greater awareness of AKI conditions, along with changes in practices in terms of renal replacement therapy, are likely to further influence data clustering and to account for part of the observed changes in incidence and outcome [5]. Hence, increasing rate of mild AKI ultimately coded as consequences of increased awareness is likely to lead to

\footnotetext{
*Correspondence: michael.darmon@aphp.fr

${ }^{1}$ Medical ICU, AP-HP, Saint-Louis University Hospital, 1 Avenue Claude Vellefaux, 75010 Paris, France
}

Full list of author information is available at the end of the article a decreased mortality induced by change in overall AKI severity in the later years.

Nonetheless, although coding-based identification of AKI is imperfect and lacks sensitivity, its specificity is fairly robust, and use of administrative dataset is a pragmatic approach to appreciate changes at national level. The study of Jang et al., although hypothesis generating, is important and further underlines need for high quality, worldwide, assessment of AKI epidemiology and of its changes over time. Ideally, these data should be adjusted for clustering effect induced by changes in practices, changes in AKI definition and heterogeneity across centers and countries, along with usual confounders. Accurate assessment of population incidence of AKI is needed to appreciate the public health burden of AKI. More research is needed to address reasons for underlying disparities among groups and reasons behind the increase in the incidence of AKI. It will also help us to understand whether AKI outcome has improved over the last decades, in way to settle achievable goals for the forthcoming years.

\section{Authors' contributions \\ MD was responsible for drafting the manuscript. EC provided critical revision of the manuscript. LZ provided critical revision of the manuscript. All authors} read and approved the final manuscript.

\section{Funding}

None.

Availability of data or materials

Not applicable.

Ethics approval and consent to participate

Not applicable.

Consent for publication

The final version of the manuscript has been approved by all of the authors. 


\section{Competing interests}

Dr. Darmon reports having received consulting fees from Sanofi and GileadKite, research support from Astute Medical and MSD and speaker fees from MSD, Gilead-Kite and Astellas. Dr. Zafrani reports having received a research grant from Jazz Pharmaceutical. The other authors declare having no conflict of interest related to this manuscript.

\section{Author details}

1 Medical ICU, AP-HP, Saint-Louis University Hospital, 1 Avenue Claude Vellefaux, 75010 Paris, France. ${ }^{2}$ Paris-Diderot Medical School, University of Paris, Paris, France. ${ }^{3}$ ECSTRA Team, Biostatistics and Clinical Epidemiology, UMR 1153 (Center of Epidemiology and Biostatistic, Sorbonne Paris Cité, CRESS), INSERM, Paris, France. ${ }^{4}$ Medical ICU, Hôtel-Dieu University Hospital, Nantes, France.

${ }^{5}$ INSERM UMR-976, Paris, France.

Received: 9 May 2019 Accepted: 17 May 2019

Published online: 27 May 2019

\section{References}

1. Hwang S, Park H, Kim Y, et al. Changes in acute kidney injury epidemiology in critically ill patients: a population-based cohort study in Korea. Ann Intensive Care. 2019. https://doi.org/10.1186/s13613-019-0534-7
2. Wald R, McArthur E, Adhikari NKJ, et al. Changing incidence and outcomes following dialysis-requiring acute kidney injury among critically ill adults: a population-based cohort study. Am J Kidney Dis Off J Natl Kidney Found. 2015;65:870-7. https://doi.org/10.1053/j.ajkd.2014.10.017.

3. Kim JA, Yoon S, Kim LY, Kim DS. Towards actualizing the value potential of Korea Health Insurance Review and Assessment (HIRA) data as a resource for health research: strengths, limitations, applications, and strategies for optimal use of HIRA data. J Korean Med Sci. 2017;32:718-28. https://doi. org/10.3346/jkms.2017.32.5.718.

4. Siew ED, Basu RK, Wunsch H, et al. Optimizing administrative datasets to examine acute kidney injury in the era of big data: workgroup statement from the 15(th) ADQI Consensus Conference. Can J Kidney Health Dis. 2016;3:12. https://doi.org/10.1186/s40697-016-0098-5.

5. Siew ED, Davenport A. The growth of acute kidney injury: a rising tide or just closer attention to detail? Kidney Int. 2015;87:46-61. https://doi. org/10.1038/ki.2014.293.

\section{Publisher's Note}

Springer Nature remains neutral with regard to jurisdictional claims in published maps and institutional affiliations.

\section{Submit your manuscript to a SpringerOpen ${ }^{\circ}$ journal and benefit from:}

- Convenient online submission

- Rigorous peer review

- Open access: articles freely available online

- High visibility within the field

- Retaining the copyright to your article

Submit your next manuscript at $\boldsymbol{\nabla}$ springeropen.com 